\title{
Technologies for the automated collection of heat stress data in sheep
}

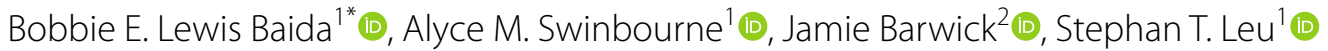 \\ and William H. E. J. van Wettere ${ }^{1}$ (1)
}

\begin{abstract}
The automated collection of phenotypic measurements in livestock is becoming increasingly important to both researchers and farmers. The capacity to non-invasively collect real-time data, provides the opportunity to better understand livestock behaviour and physiology and improve animal management decisions. Current climate models project that temperatures will increase across the world, influencing both local and global agriculture. Sheep that are exposed to high ambient temperatures experience heat stress and their physiology, reproductive function and performance are compromised. Body temperature is a reliable measure of heat stress and hence a good indicator of an animals' health and well-being. Non-invasive temperature-sensing technologies have made substantial progress over the past decade. Here, we review the different technologies available and assess their suitability for inferring ovine heat stress. Specifically, the use of indwelling probes, intra-ruminal bolus insertion, thermal imaging and implantable devices are investigated. We further evaluate the capacity of behavioural tracking technology, such as global positioning systems, to identify heat stressed individuals based on the exhibition of specific behaviours. Although there are challenges associated with using real-time thermosensing data to make informed management decisions, these technologies provide new opportunities to manage heat stress in sheep. In order to obtain accurate real-time information of individual animals and facilitate prompt intervention, data collection should be entirely automated. Additionally, for accurate interpretation on-farm, the development of software which can effectively collect, manage and integrate data for sheep producer's needs to be prioritised. Lastly, understanding known physiological thresholds will allow farmers to determine individual heat stress risk and facilitate early intervention to reduce the effects in both current and subsequent generations.
\end{abstract}

Keywords: Telemetry, Remote temperature, Heat stress, Livestock monitoring, Thermoregulation, Temperature data logger, Ovine, Animal attached sensors

\section{Background}

High ambient temperature is a major constraint to livestock productivity, such as sheep maintained in arid and semi-arid environments [1], making future farming decisions complex [2]. Annual average warming is predicted to be approximately $1.0^{\circ} \mathrm{C}$ across Australia in the

\footnotetext{
*Correspondence: bobbie.lewisbaida@adelaide.edu.au

${ }^{1}$ School of Animal and Veterinary Sciences, Davies Livestock Research

Centre, The University of Adelaide, Roseworthy Campus, Mudla Wirra Rd, Roseworthy, SA 5371, Australia

Full list of author information is available at the end of the article
}

coming decade and, depending on the level of greenhouse gas emissions, between 0.8 to $2.8{ }^{\circ} \mathrm{C}$ by 2050 , and up to $5{ }^{\circ} \mathrm{C}$ by 2070 [3]. The negative effect of rising temperature is aggravated when it is accompanied by high ambient humidity [4]. Further, global warming will result in an increase in the frequency and duration of extreme heat events, one of the major problems affecting the sustainability of livestock production worldwide [5]. Climate change influences animal agriculture in four main ways: (1) feed-grain availability and price; (2) pasture/forage production and quality; (3) direct effects 
of weather and extreme conditions on animal health, growth and reproduction; and (4) distribution of livestock diseases and pests [6]. In some scenarios and geoclimatic zones, water availability can also be influenced by temperature $[7,8]$. These impacts are especially consequential for free-ranging animals living in hot and dry areas all over the world. Although climate change presents a variety of challenges for global agriculture, the direct effects of hot conditions on animal production and wellbeing is one of the most difficult to manage and hence, is the primary focus of this review.

Production animals, such as sheep, which are exposed to high ambient temperatures $\left(>30^{\circ} \mathrm{C}\right)$ experience heat stress which consequently affects their overall productivity and reproductive performance [9]. Heat stress arises when the effective temperature of the environment exceeds the animals' upper critical temperature, which in sheep ranges from 25 to $31{ }^{\circ} \mathrm{C}$, depending on breed, age and physiological state [10]. The implementation of effective amelioration strategies requires greater understanding of the physiological and behavioural impacts of heat stress on extensively grazed sheep. Core temperature is one of the most reliable indicators of heat stress in livestock [11]. Furthermore, it is an economically significant measure due to the close association with health [12], reproductive success [9] and overall productivity [13].
To circumvent the stress associated with handling and restraint, a number of remote sensing methods have been developed for the continuous and longitudinal measurement of body temperature. These technologies aim to closely monitor body temperature in real-time, allowing for early detection of heat stress, illness or disease [14]. The advantage of this technology is that it reduces the level of human interference, improves animal welfare and provides an accurate representation of thermal status. It also allows a greater temporal and diurnal resolution of data, which is practically and physically not possible with manual measurements [15]. The main methods used to measure body temperature via remote sensing technology include vaginal and rectal probes $[16,17]$, rumen boluses [18], ear canal sensors [19] and wearable and implantable devices such as microchips [20] (Tables 1, 2 ). These methods are constantly improved and tested for efficacy in various parts of the body [20,21]. Furthermore, thermal imaging or infrared thermography (IRT) has also been used in livestock as a tool for investigating thermal status by measuring the surface temperature of an animal's infrared radiation [22-25].

In addition to temperature-sensing technology, behavioural and activity monitoring technologies are used to measure body movement and spatial behaviours. Animal attached Global Positioning Systems (GPS) or Global

Table 1 Features of cost, accuracy and data storage of different technologies used to infer ovine heat stress

\begin{tabular}{|c|c|c|c|c|c|}
\hline Technology & Model/type & Cost per unit (AUD) & Sensor accuracy & Data collection & Ovine studies \\
\hline \multirow[t]{2}{*}{$\begin{array}{l}\text { Temperature loggers } \\
\text { (thermistors/thermo- } \\
\text { couples) }\end{array}$} & $\begin{array}{l}\text { Thermochron iButton } \\
\text { (OnSolution, Maxim } \\
\text { International) }\end{array}$ & $\begin{array}{l}98+\text { software and } \\
\text { deployment strategy }\end{array}$ & $\pm 0.5^{\circ} \mathrm{C}$ & \multirow{2}{*}{$\begin{array}{l}\text { Data storage, up to } \\
6 \text { months of data in } \\
\text { memory, 1-2 year bat- } \\
\text { tery life }\end{array}$} & \multirow[t]{2}{*}[15,51,53,85,124]{} \\
\hline & $\begin{array}{l}\text { DST Micro loggers } \\
\text { (StarOddi) }\end{array}$ & $\begin{array}{l}475+\text { communication } \\
\text { box }(545), \text { Mercury soft- } \\
\text { ware }(370)+\text { deploy- } \\
\text { ment strategy }\end{array}$ & $\pm 0.06{ }^{\circ} \mathrm{C}$ & & \\
\hline $\begin{array}{l}\text { Automated tympanic } \\
\text { probes }\end{array}$ & $\begin{array}{l}\text { FeverTags }{ }^{\circledR}, \text { Cow } \\
\text { Manager, DoggTag, } \\
\text { SenseTag, TekVet }\end{array}$ & $25-40$ & $\pm 0.1{ }^{\circ} \mathrm{C}$ & $\begin{array}{l}\text { Data storage, }>2 \text { year } \\
\text { battery life }\end{array}$ & [124] \\
\hline Reticulorumen boluses & Smartstock, USA & $\begin{array}{l}70+\text { station (960) and } \\
\text { receiver (1790) }\end{array}$ & $\pm 0.2^{\circ} \mathrm{C}$ & $\begin{array}{l}\text { Wireless data transmis- } \\
\text { sion up to } 200 \mathrm{~m}\end{array}$ & {$[66,69-71,125,126]$} \\
\hline \multirow[t]{2}{*}{ Infrared Thermography } & $\begin{array}{l}\text { IRT Thermometer; VTTS- } \\
1000 \text { Tympanic Scanner } \\
\text { Exergen Corporation }{ }^{\circledR}\end{array}$ & 100 & $2{ }^{\circ} \mathrm{C}$ or $0.5 \%$ & Manual thermometry & {$[96,127]$} \\
\hline & IRT Camera & $1000-4300$ & $<0.1^{\circ} \mathrm{C} \pm 2 \%$ & $\begin{array}{l}\text { Contactless, }>3000 \mathrm{~m} \\
\text { range }\end{array}$ & {$[25,85-87,128-130]$} \\
\hline Implantable devices & $\begin{array}{l}\text { LifeChip }^{\circledR} \text { microchips } \\
\text { with BIO-THERM }{ }^{\circledR} \\
\text { sensor }\end{array}$ & $20-50$ & $\pm 0.5^{\circ} \mathrm{C}$ & $\begin{array}{l}\text { Data storage activated } \\
\text { through handheld } \\
\text { receiver }\end{array}$ & {$[15,66,86]$} \\
\hline GPS collars & $\begin{array}{l}\text { UNETracker, WildTrax, } \\
\text { EarTrax-AG }\end{array}$ & 2000 & $5-10 m$ & Data storage & {$[26,115-118]$} \\
\hline \multirow[t]{2}{*}{ Accelerometers } & $\begin{array}{l}\text { HOBO Pendant } G \text { data } \\
\text { loggers }\end{array}$ & 195 & Up to $99 \%$ & $\begin{array}{l}\text { Data storage \& wireless } \\
\text { transmission }\end{array}$ & {$[108,112,117,131]$} \\
\hline & ActiGraphs & 290 & & & [109] \\
\hline
\end{tabular}




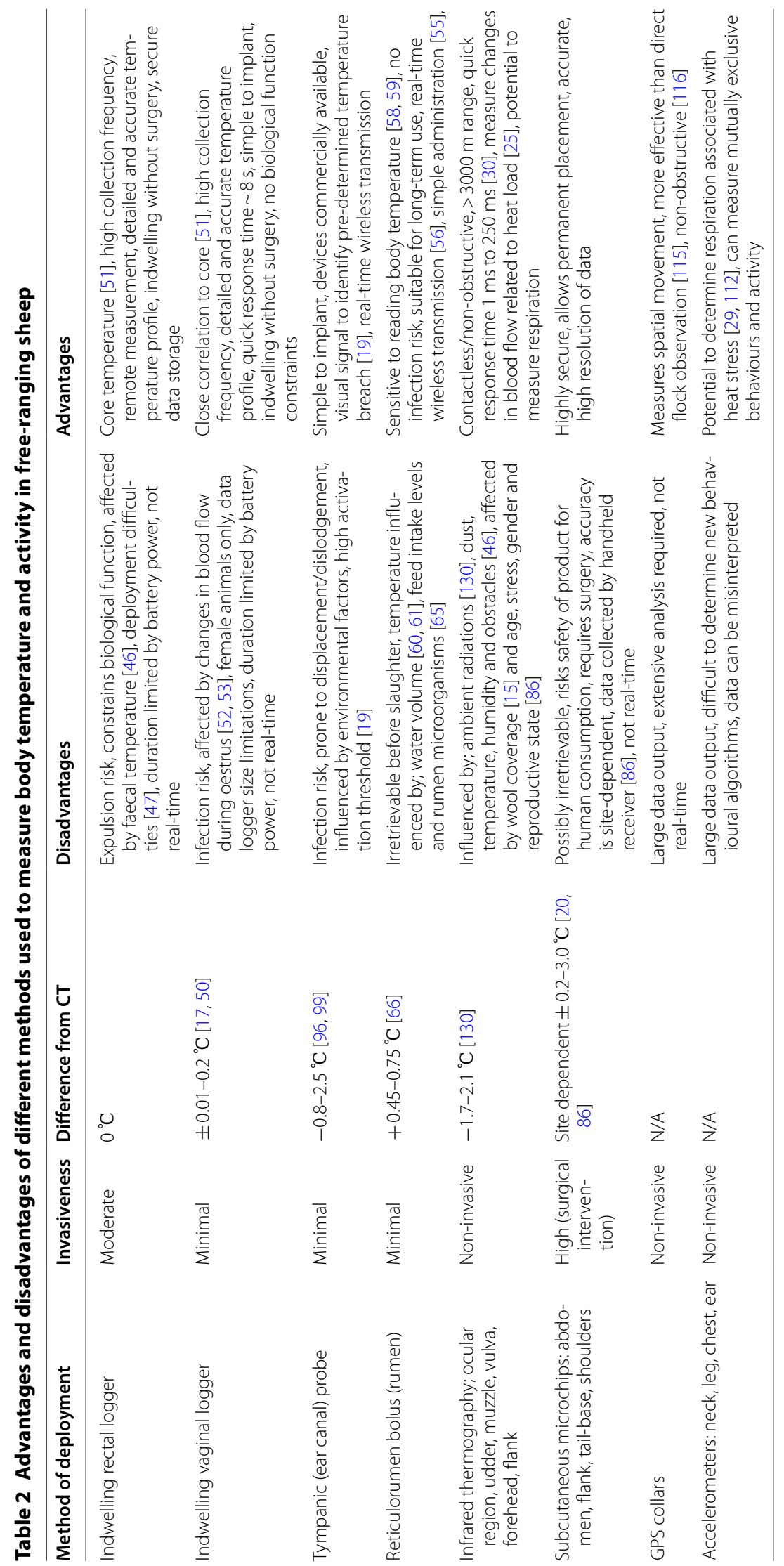


Navigation Satellite Systems (GNSS) are being adopted for the ongoing assessment of the activity levels, shelter utilisation and behavioural responses of livestock species during heat exposure [26]. For instance, tri-axial accelerometers record animal body movements and can be used to deduce different behaviours. These behaviours include, ruminating and grazing [27] and walking/running behaviours [28], as well as increased respiration rates (RR) or occurrence of 'heavy breathing' [29], a physiological response to heat stress [11]. In livestock, the majority of research relating to the use of temperature sensing technology has been conducted in cattle (see review; [30]). In contrast, the information available regarding its effectiveness in extensive sheep production systems is limited (Table 1). Continuous measurement of body temperature may be an essential factor in the effective control and management of sheep herds by not only monitoring health status of individuals, but also minimising the outcomes of heat stress. The technologies currently available for the remote identification of heat stress fall into two discrete categories; (1) monitoring body temperature to identify heat stress based on known physiological thresholds and, (2) monitoring animal behaviour to determine individual heat stress based on specific behaviours. The aim of this manuscript is to review the temperature sensing and behavioural tracking technologies available and, investigate their suitability for inferring ovine heat stress.

\section{Bioclimatic indices}

It is important to recognise that thermal stress is not initiated by ambient temperature alone, and that there are a variety of cardinal weather variables that can assist in the assessment or prediction of high heat load [31]. The Temperature-Humidity Index (THI) is the simplest approach, combining ambient temperature and relative humidity to estimate livestock productivity responses as a function of climate [32]. Using calculated THI, livestock specific safety indices are then commonly used to categorise heat stress severity; no stress ( $\mathrm{THI} \leq 67)$, mild (THI 68-74), moderate (THI 75-78), severe (THI 79-83) and extreme (THI $\geq 84)$ [33]. As temperature and humidity are often readily collected, the minimal inputs make THI, and its variants [34-36], an easy tool for retrospective studies in most regions. However, air temperature has found to be just as effective as THI for predicting core temperature [36]. Additionally, the THI excludes direct and indirect solar radiation as well as wind speed, both important weather variables that can have consequences with regard to thermoregulatory stress [37]. In turn, subsequent methods have since been developed to address these limitations by including these parameters. The Black Globe Humidity Index (BGHI) was developed to incorporate the impact of solar radiation and was found to have a stronger correlation to rectal temperature and respiration rates in dairy cows when compared to THI [38]. More recently, the Heat Load Index (HLI) was developed and is currently applied by the Australian feedlot industry as a predictive model, incorporating the contribution of black globe temperature, relative humidity and wind speed [39]. In this scenario, heat stress levels were assessed by the use of panting scores and core temperature measured by tympanic thermistors. As with THI, there is then thresholds which have been nominated as a guide for assessing heat load in cattle, ranging from thermoneutral $(\mathrm{HLI}<70)$ to extreme $(\mathrm{HLI}>96)$, with the ability to adjust the model around specific animal parameters such as age and health status [39]. Newer indices include the Comprehensive Climate Index (CCI) which uses air temperature, relative humidity, wind speed and solar radiation [40], the Equivalent Temperature Index for (dairy) Cattle (ETIC) [41] and Accumulated Heat Load (AHL) [39].

Although bioclimatic indices can act as a guide for estimating heat stress severity on livestock wellbeing, they carry a set of limitations. One of the main limitations of bioclimatic indices is the lack of relationship to the core temperature and respiratory dynamics of animals experiencing excessive heat load. Additionally, the aforementioned indices are based on measurements at a single time point and fail to incorporate the duration and intensity of heat exposure [42]. Further, the most important aspect of using bioclimatic indices as predictive models for heat stress, is the collection of accurate and representative meteorological data. Although the placement of weather stations can be in relatively close proximity to the animals at risk, some may fail to accurately represent the conditions of the pen or paddock in question [43]. Differences between weather variables are specifically evident when comparing paddock conditions with those measured by the closest government weather station, demonstrating an effect of habitat [44]. It is also possible to use incorrect threshold settings, for example, thresholds can be set as if all pens are unshaded [43]. With regard to the measurement of heat stress in sheep, research on heat load indices used in extensive sheep grazing systems is limited when compared to the research conducted on feedlot and dairy cattle. Irrespective of the available information, measuring and remotely monitoring the physiological responses, such as core temperature, is going to provide a much more informative and accurate reflection of animal wellbeing.

\section{Rectal and vaginal probes}

It is assumed that an animal's core temperature reflects the temperature of the main internal organs such as the heart, brain and viscera [30]. Rectal temperature (RT) 
has long been used to evaluate core temperature and to quantify the heat stress response in livestock [11]. Although accurate and repeatable, manual measurement of core temperature using a digital rectal thermometer only provides a cross-sectional sample due to the need to handle and restrain the animal. Another limitation is that restraint during manual temperature assessment leads to stress-induced hyperthermia and increased metabolic heat production associated with the flight response [45]. Therefore, manual thermometry is not appropriate for the assessment of continuous, longitudinal patterns of body temperature in free-range animals or those in extensive grazing systems [46]. Indwelling thermal sensors such as rectal probes have the advantage over traditional thermometry as they enable producers to remotely measure temperature changes without removing animals from production [20]. Despite a relative degree of invasiveness, indwelling rectal probes record core temperature most consistently, particularly in male animals [14]. However, external physical attachment or support is necessary to maximise stability and resist expulsion during defecation. Although this has been achieved in cattle using a tail harness [47], the concept would prove more difficult in sheep, typically lacking a comparable tail. Therefore, it is likely that the stability of rectal probes and ability to keep them stationary, as well as expulsion and faecal temperature during defecation, will limit the collection of accurate temperature data in sheep $[14,46]$.

Another common location for measuring core temperature is the vagina, which is well insulated and characterised by thermal gradients [48]. Indwelling vaginal temperature (VT) sensors demonstrate a high correlation with RT measurements [49], with differences between the two found to be negligible when using identical temperature measuring devices [50]. An extremely high correlation, as well as a clear response of both devices to lipopolysaccharide (LPS) administration, which is used to stimulate an immune response, was found when comparing the use of rectal and vaginal probes in beef heifers [16]. More recently in ewe-lambs, VT sensors were effective in measuring body temperature under grazing conditions, as well as determining shade use and the effects of various tree species on animal physiology [51] (Fig. 1). Although a small number of devices became loose or fell out, this is likely to be a sensor specific problem which could be mitigated through appropriate design

\section{A)}

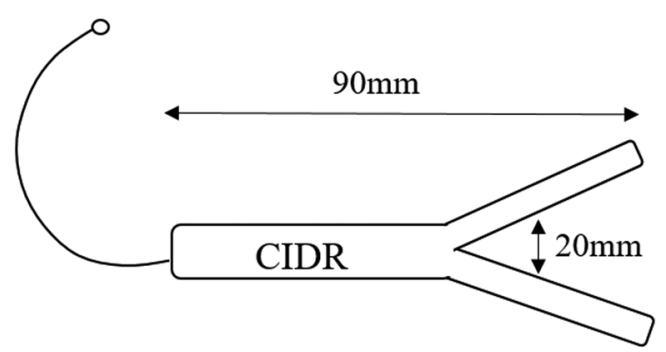

C)

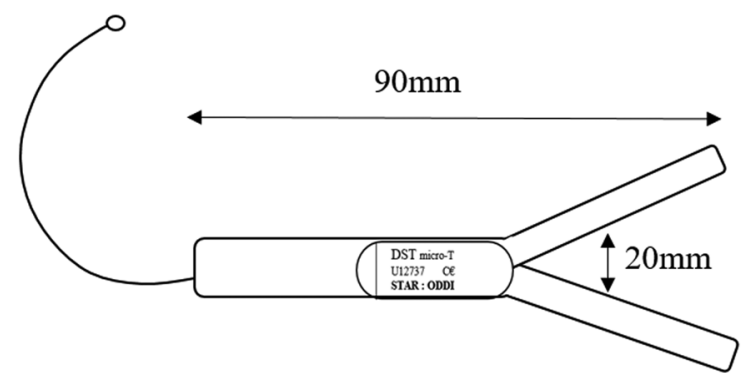

B)

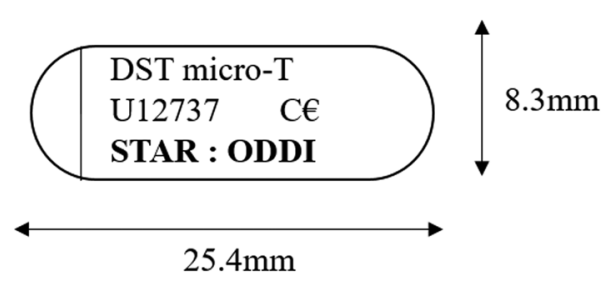

D)

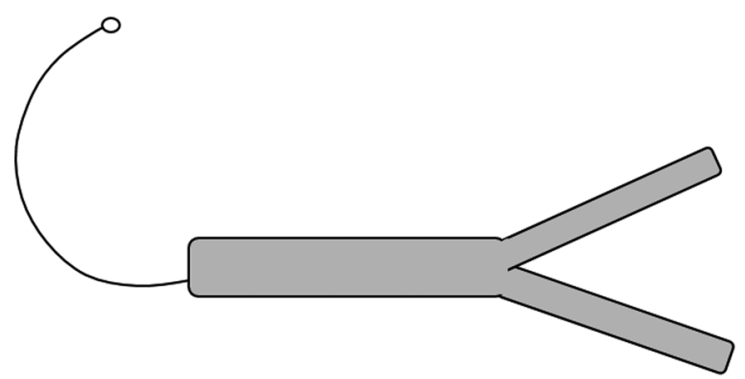

Fig. 1 The modification of a controlled internal drug release (CIDR) device and temperature logger for sheep. Device developed to monitor vaginal temperature automatically in sheep where, (a) a blank CIDR is modified to house the temperature logger, (b) dimensions of the temperature logger, (c) an opening is made and the temperature logger is inserted just before the junction of the two arms, and (d) the temperature logger and whole device is sealed with Super 33 + vinyl electrical tape. As described by Pent et al. [51] 
alterations. An important consideration with VT devices is the changes in uterine and vaginal blood flows which occur at different stages of reproduction [52]. In sheep, changes in vaginal blood flow have shown to alter VT during gestation [53], and are likely to influence VT during other stages of the oestrous cycle. Lastly, the main limitation of this technology as it currently stands, is that the data is stored on the device, preventing access to the data in real-time [14]. Therefore, technological advancements that can allow this technology to be truly automated would increase its practicality.

\section{Rumen/reticular boluses}

Over the past decade, intra-ruminal insertion of temperature sensors has emerged as a non-invasive alternative to the surgical implantation of devices [54]. Temperature loggers consisting of a chip, antenna, battery and temperature sensor are built into a bolus which is orally administered and naturally transported into the rumen [55]. This technology enables real-time data collection through instant wireless transmission [56] or stores the information until the animal is in close proximity of a receiving antenna [14]. Given their weight for use in cattle $(\sim 120 \mathrm{~g})$, ingested devices are located in the reticulum or near the junction between the rumen and reticulum [14]; however, variations in exact positioning cannot be ruled out [56]. One study investigated strategies to anchor the bolus to the rumen to ensure consistency in temperature data amongst individual animals [57]. Mostly used in cattle, rumen or reticular temperature (RuT) has been investigated as a tool for the remote measurement of core temperature (CT) [58, 59]. RuT correlated with RT and RR in beef cattle [60] and has been investigated as an indicator of heat stress in dairy cattle [61]. Although an increase in RuT in response to increasing THI was observed (Fig. 2) [61], it was reported that both water intake and milk yield had a significant influence on median RuT. This finding is supported by another study which observed the influence of water intake on RuT [60], where the effects were mitigated by excluding all RuT readings associated with drinking events $(2 \times \mathrm{SD}$ of the mean/cow). As RuT is affected by water intake, reticulorumen boluses have the potential to remotely monitor drinking events and investigate factors which may affect drinking behaviour in free ranging animals. A recent study assessed drinking events through ruminal temperature drops and found cow threshold characteristics and ambient temperature to have significant effects on drinking events [62]. Further, feed intake and milking increases the frequency of drinking events in dairy cattle [63]. More research in this area has been conducted in dairy cattle than sheep, as a reduction in water intake can decrease milk yield by up to $26 \%$ [64].

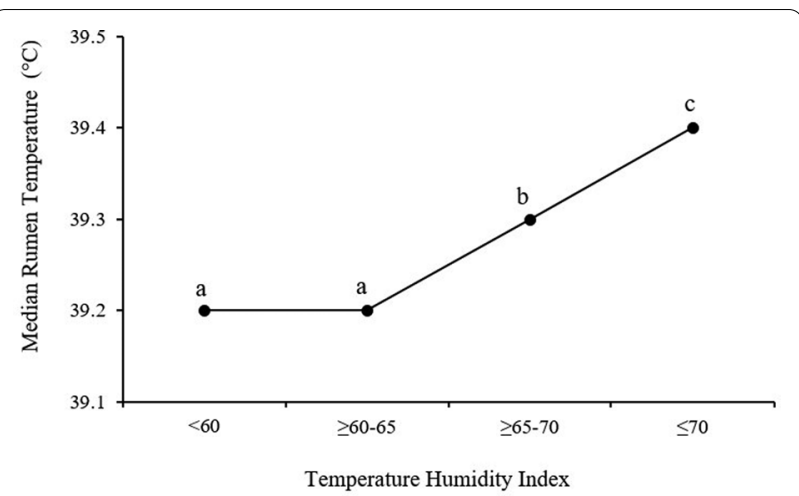

Fig. 2 Average daily median rumen temperature of cattle in relation to daily mean temperature humidity index. Daily median rumen temperature was calculated using least square means (RuT; $n=28$ cows, different letters indicate significance at $P<0.05)$. Adapted from Ammer et al. [61]

However, the detectability of drinking events could also be utilised to monitor and predict the health and physiological status of free ranging sheep under hot conditions. Another study used RuT to assess the effects of heat stress in cattle [18], concluding that RuT was influenced by breed and ambient temperature and that shade was able to reduce the magnitude of increases in RuT. The effective measurement of real-time body temperature was demonstrated; however, despite reductions in rumen temperature [58], water intake was not investigated, and was likely to have impacted data validity.

Despite the potential impact of hyperthermia on rumen function in sheep [65], literature surrounding the use of RuT to investigate heat stress in sheep is scarce. One study found RuT to consistently exceed CT by between 0.45 and $0.75^{\circ} \mathrm{C}$ in shorn and fleeced sheep under varying environmental conditions [66]. However, as the method for measuring CT was invasive in nature, the sample size was low ( $n=8 /$ treatment). The same authors compared $\mathrm{RuT}$ and CT in cattle housed in climate controlled rooms and found RuT to be consistently $1{ }^{\circ} \mathrm{C}$ higher than CT, which was sustained throughout elevated ambient temperatures [67]. One of the impacts which heat stress has on rumen function, is unfavourable changes in the microbiota profile which is heavily influenced by feed intake and diet composition [65]. Although it has previously been shown that RuT exceeds CT by approximately $2{ }^{\circ} \mathrm{C}$, this difference can be reduced to $0.7^{\circ} \mathrm{C}$ during fasting [68]. The microbial activity associated with these factors is the likely cause of discrepancies in measured differences between RuT and CT [56]. Although the ability of rumen boluses to accurately reflect $\mathrm{CT}$ remains dubious, this technology may be an extremely valuable tool for monitoring the rumen ecosystem by measuring 
other factors associated with hyperthermia and rumen function. For example, changes in diet composition has the potential to reduce the amount of heat released during feed fermentation and improve heat tolerance [69]. It has also been demonstrated that different breeds regulate RuT differently [18] and that thermoregulatory capacity varies among individuals of the same breed, effected by age and physiological state [70]. Lastly, despite some variations in retention rate depending on the bolus size in sheep [71], the devices can be safely retrieved at slaughter ensuring the animal remains safe for human consumption.

\section{Thermal imaging/infrared thermography}

Thermal imaging, also known as IRT, is a non-invasive, contactless technique which measures real-time surface temperature distribution [72]. Since its introduction to human medicine in 1956 [73], this technology has revolutionised the field of temperature measurement in the livestock industry, and has potential to be a useful tool for monitoring animal body temperature [24]. Thermographic images can be used to demonstrate an increase in body temperature and changes in blood flow related to stressful environmental conditions such as high heat load (Fig. 3) [74]. Due to the non-obstructive nature, this technology is well-suited for the assessment of stress and welfare [75] and has been used as a diagnostic tool to predict heat stress [23]. With regard to well insulated animals such as sheep, it is known that environmental heat exchange is heavily impacted by fleece length [66]. One effect of shearing is that it causes the skin to thicken which then influences heat transfer at the surface of the skin [15]. Despite fleeced sheep having insulation against environmental heat gain [76], shorn sheep tolerate hot-humid conditions better than fleeced sheep, whilst fleeced sheep have improved tolerance to hot-dry conditions [66]. Consequently, peripheral temperature measured through IRT would vary depending on the presence or absence of wool when considering skin as the thermoregulatory organ. IRT is commonly used in the veterinary sciences to identify infection $[77,78]$ lameness in horses [79], mastitis in both sheep [80] and cattle [81] as well as assess scrotal temperature in buffalo [82]. Additionally, studies have assessed the use of IRT in livestock to determine heat tolerance $[24,25]$, thermal thresholds [83] and to predict the effects of heat stress on reproductive output [84].

With regard to using IRT to accurately measure body temperature, different regions of the body have varying degrees of correlation to RT as well as association with ambient temperature [22, 85]. For example, in cattle, forehead IRT had the highest association with RT $(r=0.90)$ and also showed the highest association with THI $(r=0.81)$, followed by the right and left flank regions ( $r=0.85$ and 0.81 , respectively) [22]. Eye temperature of hair sheep was strongly correlated to VT $(r=0.77)$ and

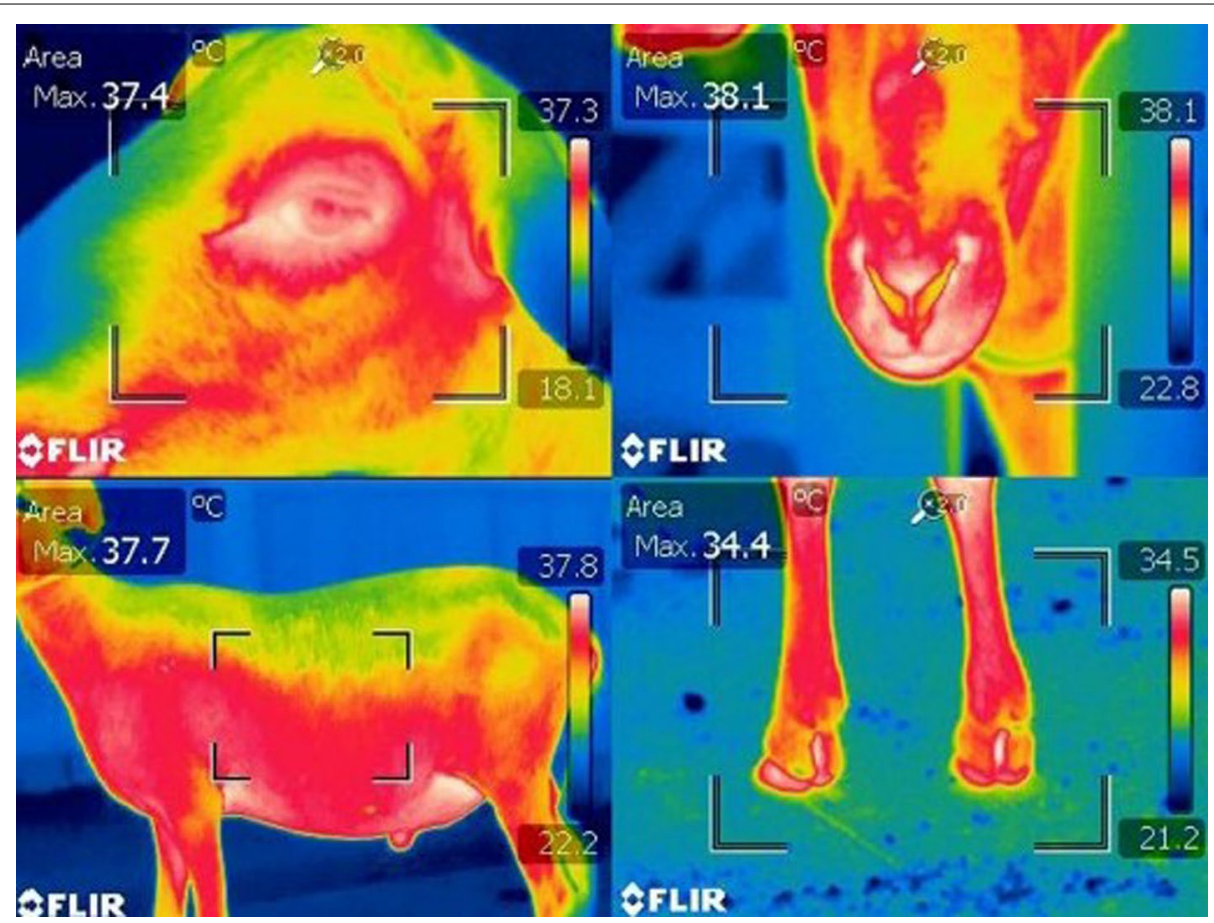

Fig. 3 Temperature gradients of specific regions of a sheep using infrared thermography. Sourced with permission from McManus et al. [74] 
RT ( $r=0.76)$ [85]. While skin locations, such as eye base, eye region and udder, may be the best thermal window, the reliability of these locations may be affected by age and stressors, as well as gender and reproductive state. This notion is supported by an earlier study, which found that ocular IRT images were correlated with RT in rams but not ewes [86]. A limitation of ocular IRT was that ocular temperature was significantly lower than core temperature and not able to detect short-term changes of temperature. In contrast, IRT was effective in detecting small temperature variations during different phases of the oestrous cycle in ewes using vulva and muzzle temperature [87].

Heat dissipation through respiration is an important thermoregulatory mechanism for sheep [1]. To circumvent the difficulties associated with evaluating $R R$ under field conditions, panting score indices have been developed [88]. While trying to predict heat stress events in feedlot cattle, both mean body surface temperature and panting score increased with THI [23], confirming a close relationship between body surface temperature and panting. Although panting score can be used to assess the heat load status of sheep, it still requires labour intensive visual appraisal. Additionally, the main limitation of quantifying respiration based on panting scores is that they are subjective and thus, it is advantageous to include measurements of core temperature as a comparative, objective measure of thermal status. Surface temperatures measured by IRT in lambs showed a high, positive correlation to RR when measured at the flank $(r=0.72)$, rump $(r=0.75)$ or nose $(r=0.68)$, as well as RT temperatures correlated with IRT images of the rump (0.62) and nose $(r=0.72)$ [25]. Due to the medium-high correlations with traditional heat tolerance measures (RT and $\mathrm{RR}$ ), these findings demonstrate that IRT may be efficient in inferring heat stress in lambs. Lastly, IRT has also been used for the remote measurement of RR in dairy cows with little difference observed between RR collected by IRT and measures collected through direct observation or video recording methods [89].

To summarise, the areas for IRT images to best resemble CT vary within and between species. Computation of software-based assignment of body temperature is necessary for IRT to be used on a large-scale commercial setting [30]. It is also important to consider appropriate camera positioning, how IRT is affected by ambient temperature and UV light, as well as the high costs and labour associated with use of this technology $[14,75]$. In addition to its use for measuring body temperature, automating the extraction of RR from IRT images could also make it a valuable on-farm tool for the management of heat stress; however, further research is required to test its efficacy in sheep.

\section{Subcutaneous temperature sensors/implantable devices}

A range of subcutaneous microchips and other implantable devices are also being developed for the continuous measurement of body temperature in livestock [20, 90, 91]. Typically, microchip transponders are injected under the skin and activated through a handheld receiver where the temperature reading is then relayed instantaneously [92]. Temperature sensing microchips have been used as a measure of $\mathrm{CT}$ in sheep to determine the relationship with RuT over a range of environmental temperatures [66]. In this instance, the temperature loggers were surgically implanted into the peritoneum region and changes were evident when sheep were exposed to hot conditions and when shorn and unshorn sheep were compared. The peritoneum region, also referred to as intra-peritoneal or intraabdominal, is the most common site for implants when long-term body temperature profiles are desirable [46]. Some manufacturers recommend adding $2{ }^{\circ} \mathrm{C}$ to microchip temperatures to obtain a better estimate of $\mathrm{CT}$ [20]; however, the temperature difference depends on the site of the body [20].

Microchip devices have been used to measure temperature at different body sites in goats that were kept at different ambient temperatures [20]. Temperatures measured by the microchip implanted into the retroperitoneal region showed the highest association (mean $0.2{ }^{\circ} \mathrm{C}$ lower) with both RT and CT (measured in the abdominal cavity), when compared to the groin, semimembranosus muscle, flank and shoulder [20]. Another study found that subcutaneous microchips inserted under the tail of ewes (Fig. 4) showed a significant correlation with RT; however, they were found to be approximately $1.5{ }^{\circ} \mathrm{C}$ lower on average [86]. The aforementioned studies suggest a relationship between $\mathrm{CT}$ and the subcutaneous temperature measures. Hence, the measures of temperature sensitive microchips may be used to estimate core temperature, if implanted in the appropriate anatomical locations [20]. Other similar types of implantable devices are being investigated; however, all require surgical procedures for implantation. In addition to their invasive nature, subcutaneous temperature is influenced by environmental conditions and physiological state as this directly effects the flow of blood to the skin [93]. Ways to measure body surface temperature through wearable devices may be an appropriate alternative to subcutaneous implants. One study attached a wearable thermometer to the leg of cattle and reported a high correlation between the temperature measured at close contact to the muscle and RT [94]. 


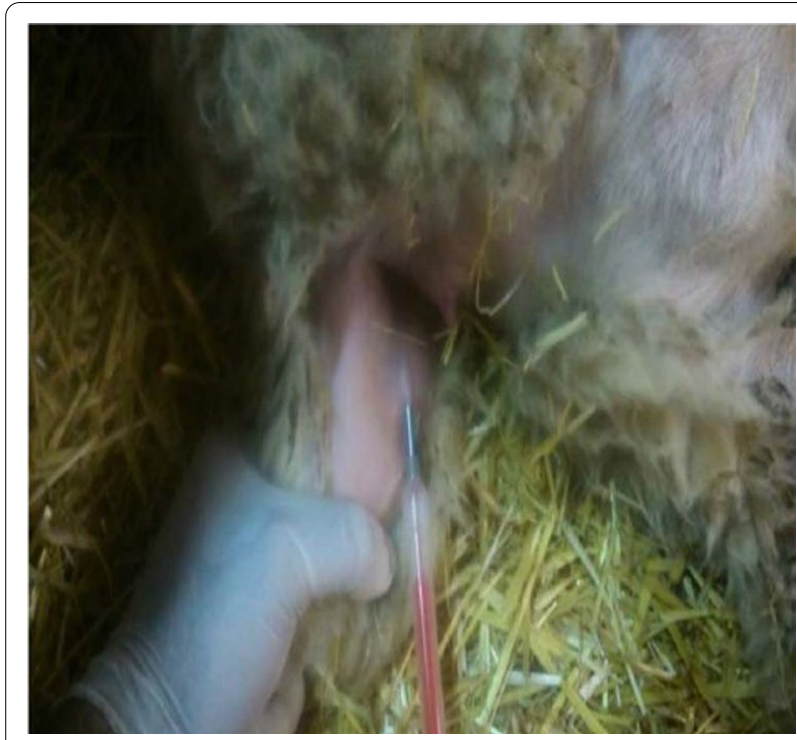

Fig. 4 Subcutaneous temperature sensing transponder inserted underneath the tail of a sheep to measure body temperature. Sourced with permission from Abecia et al. [86]

\section{Tympanic temperature}

Despite being considered as a reliable indicator of CT in humans at the level of the hypothalamus [95], the use of tympanic temperature (TT) as a measure of body temperature in domesticated livestock has not been thoroughly investigated. TT is taken by inserting a thermometer into the external ear canal and directing the device towards the tympanic membrane [96]. More research using ear temperature monitoring systems has been conducted in cattle than sheep, with the primary purpose to detect fever due to illness $[19,97]$. Temperature sensing ear tags $\left(\right.$ Fever $\mathrm{Tag}^{\circledR}$ ) were used to detect illness in calves; however, tag placement and probe dislodgment limited the detection of sick calves [19]. Additionally, the tags were not tested under different environmental conditions such as high ambient temperature and/or direct sunlight which may be misinterpreted as fever. The same technology (Fig. 5) has been used to detect bovine respiratory disease (BRD) in feedlot cattle, concluding that treating animals on the basis of high TT through Fever Tag $^{\circledR}$ alert was just as effective as the traditional pull and treat method based on RT and signs of BRD as monitored by experienced personnel [97]. In order for tympanic temperature tags to be useful to detect elevated body temperature and hence the onset of heat stress, more research is required, particularly on the influence of ambient conditions, as well as the durability of these tags.

With regard to heat stress, collection of hourly TT under thermoneutral and heat stress conditions has enabled the efficacy of restricted feeding regimes and sprinkler use to be tested as strategies to reduce the effects of heat stress in feedlot cattle [98]. Changes in TT were recorded in response to both sprinkler use and alteration in feeding regime, suggesting that it may be an effective tool to monitor physiological responses. Although care is taken to ensure secure and consistent placement of the data logger within the ear canal, inconsistencies and displacement are to be expected. For this reason, smaller, self-contained temperature loggers have been designed to record TT in cattle [99]. However, as a result of the poor recovery rate and large variability in temperature profiles both within and between animals, more research is required to characterise TT profiles. Lastly, although most of these technologies transmit data wirelessly for remote use, current designs make it difficult to measure TT continuously for more than several days due to
A)

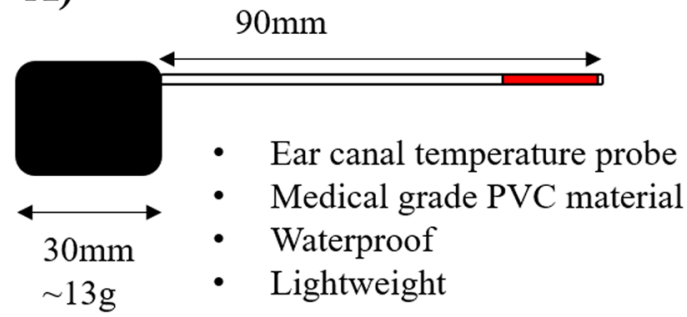

B)

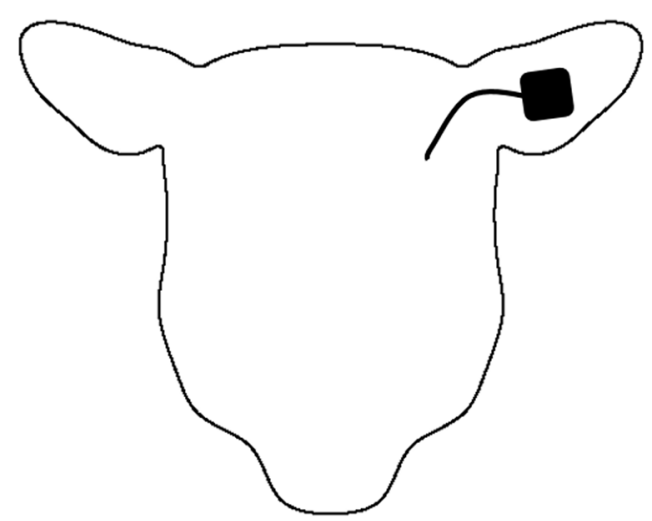

Fig. 5 Tympanic temperature probe for the automated measurement of body temperature in sheep. Schematic of (a) FeverTag before application, and (b) after application. Probes are inserted into the ear canal and the attached external tag is secured using an ear tag applicator. Adapted from Richeson et al. [97] 
displacement of the temperature sensor and potential risk of infection [100].

\section{Accelerometers}

The use of automated systems for behavioural monitoring is of increasing importance to both researchers and farmers, due to its many advantages over visual appraisal. Monitoring the behaviour of an animal has the potential to increase the efficiency of animal production through improved management and early detection of illness, disease or stress [101]. Accelerometer tags are small and lightweight which ensures minimal obstruction or interference with an animal's natural behaviour. These tags measure linear acceleration along one or more axes and can accurately depict animal body movement [102]. Additionally, the sampling frequency can influence the accuracy of identifying a certain behaviour, for instance grazing, and should be carefully selected [103]. Accelerometers consist of integrated data loggers and can be attached to various parts of the body, depending on the behaviours which are being observed [104, 112] (Fig. 6). For example, an accelerometer sensor positioned under the lower jaw measured grazing behaviour accurately in sheep [105]. Further, sensors attached to the ear, were used to correctly identify grazing, standing and walking in sheep with an accuracy of $94 \%, 96 \%$ and $99 \%$, respectively [106].

More studies have been conducted to classify cattle behaviour compared to sheep behaviour [103]. Simple behavioural classification used in conjunction with GPS tracking in sheep has led to the distinguishability between "active" and "inactive" behaviour which mainly represents grazing and recumbency [107]. More complex behaviours such as rumination [27], kicking and foot movements [89], grazing, standing and walking [106] as well as laying down and running [28] have been successfully classified using accelerometers. More recently, accelerometers have been used to identify behavioural changes in ewes during parturition [108]. Furthermore, the development of commercially available activity monitors known as ActiGraphs are being adopted for research in both human and animal health. Unlike standard accelerometers, ActiGraphs include a Bluetooth function for measuring proximity and have been used to on ewes and rams during joining to indicate the birth date of lambs [109]. In addition, this Bluetooth technology has been used to determine maternal pedigree and ewe-lamb spatial relationships in extensive farming systems [110]. These flagship activity monitors are a discrete way of measuring mating behaviour and could be used to monitor the effects of hot conditions on ewe-ram interactions throughout the joining period.
The use of accelerometer and Bluetooth technology to identify behaviours directly indicative of heat stress has not been thoroughly investigated. $R R$ is one of the primary physiological responses to heat stress and can be responsible for up to $60 \%$ of total body heat loss [1]. Measurements of RR are widely used to evaluate and quantify heat stress through direct or remote observation of animals through counting the number of flank movements in a $60 \mathrm{~s}$ period (breaths/min) [11]. Although it has proven an effective measure of heat stress in livestock, it can become difficult to accurately assess at higher temperatures as RR can increase by around 3 breaths/min for every $1{ }^{\circ} \mathrm{C}$ increase in ambient temperature [111]. Additionally, manual collection of RR data is labour intensive and on-farm application is relatively impractical. One study reported an approximate $10 \%$ increase in $\mathrm{RR}$ for every $0.5^{\circ} \mathrm{C}$ rise in VT when accelerometer-based tags were used to quantify heavy breathing in dairy cows [29]. The use of accelerometers to quantify RR in sheep has not yet been validated. Nevertheless, accelerometers could be a promising technology to identify heat stress in extensive sheep production systems.

\section{GPS tracking}

GPS technology allows for the remote monitoring of animal movement, thus providing researchers and farmers with an insight into the spatial behaviour patterns of freeranging livestock. Monitoring the behaviour of livestock in extensive grazing systems can assist in managing both the animal and its interactions with the environment [113]. The popularity of GPS for tracking animal movement has increased since the mid-1990s with a total of 20 experiments published between 2011 and 2015 on sheep alone (see review; [114]). Its use for behavioural monitoring is more effective than direct flock observation [115], and there are no significant long-term effects on the natural behaviour of paddocked ewes [116]. In livestock production research, GPS tracking collars are mostly used for the assessment of grazing behaviours and distribution patterns [117], as well as identifying the presence of grazing or recumbent behaviour [107]. GPS collars have also been used to track shelter utilisation in Merino ewes [26], where sheep used sheltered areas significantly more often than the remainder of the paddock. Additionally, GNSS technology has been used to identify the onset of oestrus, through a period of increased movement speed followed by a return to 'normal' activity [118].

With reference to environmental conditions, sheep will seek shelter during periods of both heat [119] and cold stress [26], suggesting that the wellbeing of sheep may be compromised if inadequate shade or shelter is provided. The availability of shade to reduce radiation load is recognised as a necessary management tool to reduce the 


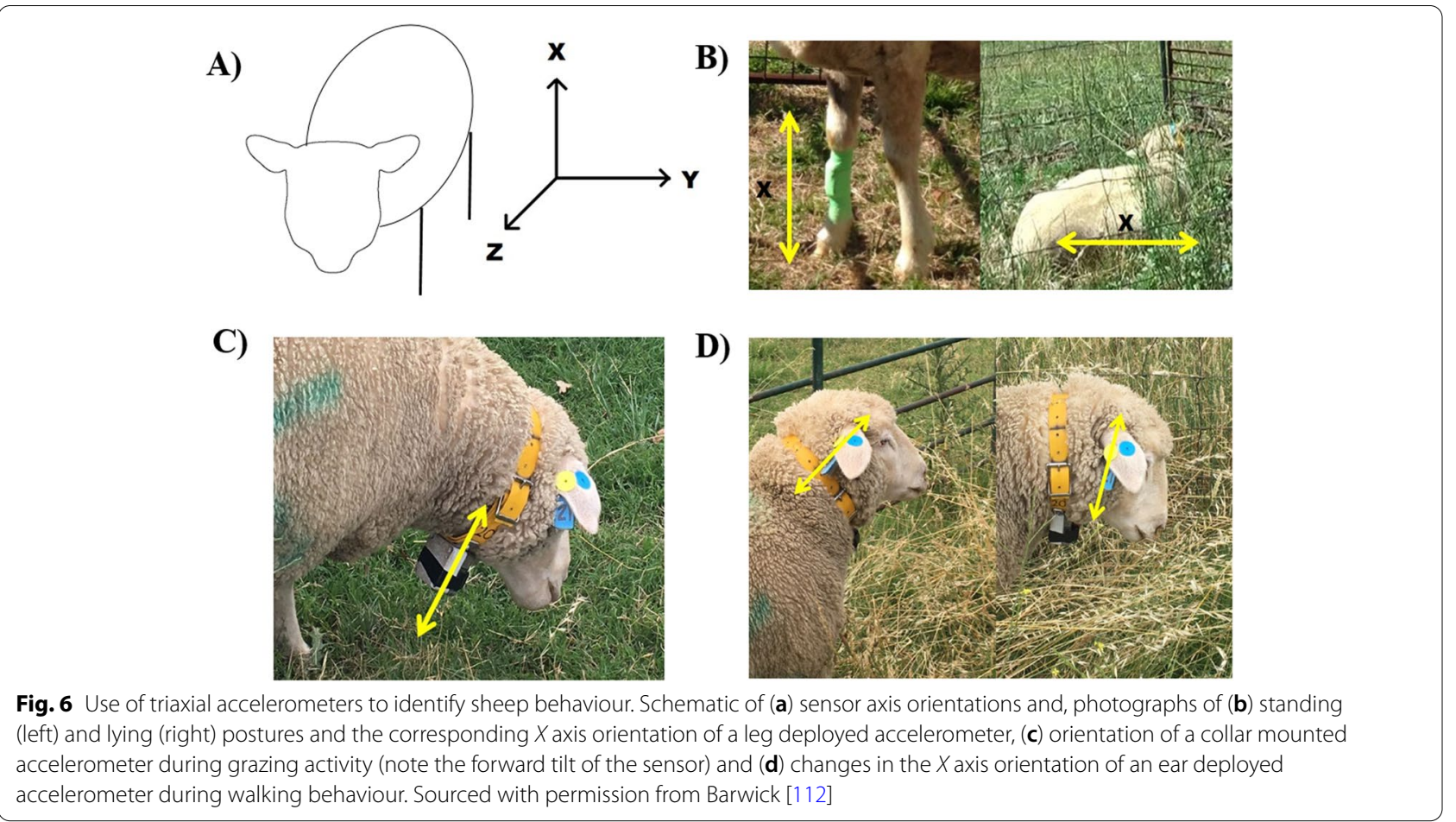

effects of heat stress among livestock [120]. Through the assessment of GPS data, shade usage and preference can be mapped within a grazing herd to better manage them under heat load. Another environmental modification to reduce the effects of heat stress in extensive grazing systems is the strategic positioning of water points through assessment of GPS data. One study using GPS collars found that Merino sheep travelled quicker and further from water on cool days compared to warm and hot days [121]. This is consistent with literature surrounding the behaviour of livestock under heat load, suggesting they adjust their behaviour during hot weather to facilitate improved thermoregulation and energy conservation $[122,123]$. Although one study compared the effects of behaviour and thermal status in free-ranging Merinos [119], environmental monitoring was carried out through manual observation rather than the use of remote tracking technology. Thus, pairing the use of GPS tracking with longitudinal, remote measures of body temperature may provide valuable insight into how different behaviours such as shade seeking or grazing modulate individual body temperatures and maintain homeothermy in pasture-based sheep production systems.

\section{Summary and conclusions}

Methods to circumvent problems associated with human presence during data collection is of increasing importance to animal researchers and farmers. Body temperature is the most important parameter for assessing heat stress among domestic livestock species and is associated with health, well-being and reproductive success. Automated temperature-sensing technology has the potential to provide continuous, real-time measurements of body temperature in livestock for a longitudinal representation of herd thermal status. This would allow for the detection of heat stress thereby facilitating prompt management intervention which could prevent associated animal losses and improve farm productivity. Before we can bridge the gap between research and industry, there are a number of important considerations. First and foremost, true automation of data collection should be a priority. Wireless transmission of real-time data is essential in providing producers with the relevant information which facilitates informed management decisions in relation to reducing the effects of heat stress as the event is occurring. Additionally, sensitivity, accuracy and variability of temperature measurements must be wellunderstood. To evade the effects of individual variation, measurements at the animal level would be the most useful in managing heat stress. Considering that individual animal variation is likely to exist at stable body temperatures, collecting longitudinal temperature data will enable specific body temperature thresholds to be established. The development of predictive model software which facilitates ease of data collection, management and integration would be a key milestone in adopting 
this technology at an industry level. The associated costs of these technologies and their comparable relationship to core temperature is likely to be a key determinant in which technologies provide the most helpful information in preventing and managing heat stress.

\section{Abbreviations}

GPS: Global Positioning Systems; GNSS: Global Navigation Satellite Systems; RR: Respiration Rate; RT: Rectal Temperature; VT: Vaginal Temperature; CIDR: Controlled Internal Drug Release; RuT: Rumen Temperature; CT: Core Temperature; THI: Temperature Humidity Index; IRT: Infrared Thermography; TT: Tympanic Temperature; BRD: Bovine Respiratory Disease; BGHI: Black Globe Humidity Index; HLI: Heat Load Index; CCl: Comprehensive Climate Index; ETIC: Equivalent Temperature Index for Cattle; AHL: Accumulated Heat Load.

\section{Acknowledgments}

Not applicable.

\section{Authors' contributions}

Author contributions are listed below. All authors have read and agreed to the published version of the manuscript. WHEJ van Wettere-Conceptualisation, Contribution of knowledge, Writing — original draft, review and editing, Supervision, Acquisition of research information. AM Swinbourne-Conceptualisation, Contribution of knowledge, Writing - original draft, review and editing, Supervision, Acquisition of research information. ST Leu-Conceptualisation, Contribution of knowledge, Writing - original draft, review and editing, Supervision, Acquisition of research information. J Barwick-Contribution of knowledge, Writing —original draft, review and editing, Acquisition of research information. BE Lewis Baida-Conceptualisation, Contribution of knowledge, Writing - original draft, review and editing, Acquisition of research information.

\section{Funding}

The corresponding author, BE Lewis Baida, holds a Research Training Program Stipend and is supported by a top-up scholarship granted by the Davies Livestock Research Centre. Additionally, this author was the recipient of a small seed grant funded by the School of Animal and Veterinary Sciences, University of Adelaide, Roseworthy Campus. Lastly, senior author, ST Leu, receives funding from the Australian Research Council (DE170101132).

\section{Availability of data and materials}

Data sharing is not applicable to this article as no datasets were generate or analysed during the current study.

\section{Ethics approval and consent to participate}

Not applicable.

\section{Consent for publication}

Not applicable.

\section{Competing interests}

The authors declare that they have no competing interests.

\section{Author details}

${ }^{1}$ School of Animal and Veterinary Sciences, Davies Livestock Research Centre, The University of Adelaide, Roseworthy Campus, Mudla Wirra Rd, Roseworthy, SA 5371, Australia. ${ }^{2}$ School of Environmental and Rural Science, Precision Agriculture Research Group, University of New England, Elm Avenue, Armidale, NSW 2351, Australia.

Received: 21 July 2020 Accepted: 7 December 2020

Published online: 07 January 2021

\section{References}

1. Marai IFM, El-Darawany AA, Fadiel A, Abdel-Hafez MAM. Physiological traits as affected by heat stress in sheep-a review. Small Rumin Res. 2007;71:1-12. https://doi.org/10.1016/j.smallrumres.2006.10.003.

2. Meat and Livestock Australia. Climate change and variability. 2020. https://www.mla.com.au/research-and-development/Environmen t-sustainability/climate-change-and-variability/\#. Accessed 16 June 2020.

3. CSIRO. Climate projections. 2019. https://www.climatechangeinaustr alia.gov.au/en/climate-projections/. Accessed 16 June 2020.

4. Abdel-Hafez MAM. Studies on the reproductive performance in sheep (PhD Thesis). Zagazig, Egypt: Zagazig University; 2002.

5. Prasad CS, Malik PK, Bhatta R. Overview. In: Malik PK, Bhatta R, Takahashi J, Kohn RA, Prasad CS, editors. Livestock production and climate change. Wallingford: CABl; 2015. p. 1-7.

6. Rötter RP, Geijn VDSC. Climate change effects on plant growth, crop yield and livestock. Clim Change. 1999;43:651-81. https://doi. org/10.1023/A:1005541132734.

7. Nardone A, Ronchi B, Lacetera N, Ranieri MS, Bernabucci U. Effects of climate changes on animal production and sustainability of livestock systems. Livest Sci. 2010;130:57-69. https://doi.org/10.1016/j.livsc i.2010.02.011.

8. Rojas-Downing MM, Nejadhashemi AP, Harrigan T, Woznicki SA. Climate change and livestock: Impacts, adaptation, and mitigation. Climate Risk Manag. 2017:16:145-63.

9. Kumar D, De K, Sejian V, Naqvi SMK. Impact of climate change on sheep reproduction. In: Sejian V, Bhatta R, Gaughan JB, Malik PK, Naqvi SMK, Lal R, editors. Sheep production adapting to climate change. Singapore: Springer Nature; 2017. p. 71-93.

10. Hopkins PS, Knights Gl, Le Feuvre AS. Studies of the environmental physiology of tropical merinos. Aust J Agric Res. 1978;29:161-71. https ://doi.org/10.1071/AR9780161.

11. Alhidary I, Shini S, Al Jassim R, Gaughan J. Physiological responses of australian merino wethers exposed to high heat load. J Anim Sci. 2012:90:212-20. https://doi.org/10.2527/jas.2011-3972.

12. St-Pierre NR, Cobanov B, Schnitkey G. Economic losses from heat stress by us livestock industries. J Dairy Sci. 2003;86:52-77. https://doi. org/10.3168/jds.S0022-0302(03)74040-5.

13. Collier RJ, Doelger SG, Head HH, Thatcher WW, Wilcox CJ. Effects of heat stress during pregnancy on maternal hormone concentrations, calf birth weight and postpartum milk yield of holstein cows. J Anim Sci. 1982:54:309-19. https://doi.org/10.2527/jas1982.542309x.

14. Koltes JE, Koltes DA, Mote BE, Tucker J, Hubbell DS. Automated collection of heat stress data in livestock: new technologies and opportunities. Trans Anim Sci. 2018;2:319-23. https://doi.org/10.1093/tas/txy061.

15. Kearton TR, Doughty AK, Morton CL, Hinch GN, Godwin IR, Cowley FC. Core and peripheral site measurement of body temperature in short wool sheep. J Therm Biol. 2020. https://doi.org/10.1016/j.jther bio.2020.102606.

16. Burdick NC, Carroll JA, Dailey JW, Randel RD, Falkenberg SM, Schmidt TB. Development of a self-contained, indwelling vaginal temperature probe for use in cattle research. J Therm Biol. 2012;37:339-43. https:// doi.org/10.1016/j.jtherbio.2011.10.007.

17. Lees AM, Lea JM, Salvin HE, Cafe LM, Colditz IG, Lee C. Relationship between rectal temperature and vaginal temperature in grazing bos taurus heifers. Animals. 2018;8:156-64. https://doi.org/10.3390/ani80 90156.

18. Lees AM, Lees JC, Lisle AT, Sullivan ML, Gaughan JB. Effect of heat stress on rumen temperature of three breeds of cattle. Int J Biometeorol. 2018:62:207-15. https://doi.org/10.1007/s00484-017-1442-x.

19. McCorkell R, Wynne-Edwards K, Windeyer C, Schaefer A. Limited efficacy of fever tag ${ }^{\circledR}$ temperature sensing ear tags in calves with naturally occurring bovine respiratory disease or induced bovine viral diarrhea virus infection. Can Vet J. 2014:55:688-90.

20. Torrao NA, Hetem RS, Meyer LC, Fick LG. Assessment of the use of temperature-sensitive microchips to determine core body temperature in goats. Vet Rec. 2011;168:328-34. https://doi.org/10.1136/vr.c6200.

21. Neethirajan $S$. Recent advances in wearable sensors for animal health management. Sens Biosensing Res. 2017;12:15-29. https://doi. org/10.1016/j.sbsr.2016.11.004. 
22. Salles MS, da Silva SC, Salles FA, Roma LC Jr, ElFaro L, Lean BMPA, et al. Mapping the body surface temperature of cattle by infrared thermography. J Therm Biol. 2016;62:63-9. https://doi.org/10.1016/j.jther bio.2016.10.003.

23. Unruh EM, Theurer ME, White BJ, Larson RL, Drouillard JS, Schrag N. Evaluation of infrared thermography as a diagnostic tool to predict heat stress events in feedlot cattle. Am J Vet Res. 2017;78:771-7. https://doi. org/10.2460/ajvr.78.7.771.

24. Brown-Brandl TM, Eigenberg RA, Purswell JL, editors. Determining heat tolerance in finishing pigs using thermal imaging. IX International Livestock Environment Symposium; 2012: American Society of Agricultural and Biological Engineers.

25. MCManus CM, Bianchini E, Paim TDP, De Lima FG, Neto JB, Castanheira $M$, et al. Infrared thermography to evaluate heat tolerance in different genetic groups of lambs. Sensors. 2015;15:17258-73. https://doi. org/10.3390/s150717258.

26. Taylor DB, Schneider DA, Brown WY, Price IR, Trotter MG, Lamb DW, et al. Gps observation of shelter utilisation by merino ewes. Anim Prod Sci. 2011;51:724-37. https://doi.org/10.1071/an11025.

27. Wolfger B, Timsit E, Pajor EA, Cook N, Barkema HW, Orsel K. Accuracy of an ear tag-attached accelerometer to monitor rumination and feeding behavior in feedlot cattle. J Anim Sci. 2015;93:3164-8. https://doi. org/10.2527/jas.2014-8802.

28. Alvarenga FAP, Borges I, Palkovič L, Rodina J, Oddy VH, Dobos RC. Using a three-axis accelerometer to identify and classify sheep behaviour at pasture. Appl Anim Behav Sci. 2016;181:91-9. https://doi.org/10.1016/j. applanim.2016.05.026.

29. Bar D, Kaim M, Flamenbaum I, Hanochi B, Toaff-Rosenstein RL. Technical note: accelerometer-based recording of heavy breathing in lactating and dry cows as an automated measure of heat load. J Dairy Sci. 2019;102:3480-6. https://doi.org/10.3168/jds.2018-15186.

30. Sellier N, Guettier E, Staub C. A review of methods to measure animal body temperature in precision farming. Am J Agric Sci Tech. 2014;2:7499. https://doi.org/10.7726/ajast.2014.1008.

31. Finocchiaro R, van Kaam JBCHM, Portolano B, Misztal I. Effect of heat stress on production of mediterranean dairy sheep. J Dairy Sci. 2005;88:1855-64. https://doi.org/10.3168/jds.S0022-0302(05)72860-5.

32. Lallo C, Cohen J, Rankine D, Taylor M, Cambell J, Stephenson T. Characterizing heat stress on livestock using the temperature humidity index (thi) - prospects for a warmer caribbean. Reg Environ Change. 2018;18:2329-40. https://doi.org/10.1007/s10113-018-1359-x.

33. Livestock Conservation Inc. Patterns of transit losses. Omaha, NEB. 1970.

34. Rashamol VP, Sejian V, Pragna P, Lees AM, Bagath M, Krishnan G, et al. Prediction models, assessment methodologies and biotechnological tools to quantify heat stress response in ruminant livestock. Int J Biometeorol. 2019. https://doi.org/10.1007/s00484-019-01735-9.

35. Hahn GL, Gaughan JB, Mader TL, Eigenberg RA. Thermal indices and their applications for livestock environments. In: DeShazer JA, editor. Livestock energetics and thermal environmental management. MI, USA: ASABE; 2009. p. 113-30.

36. Dikmen $S$, Hansen P. Is the temperature-humidity index the best indicator of heat stress in lactating dairy cows in a subtropical environment? J Dairy Sci. 2009:92:109-16.

37. Walsberg GE, Wolf BO. Effects of solar radiation and wind speed on metabolic heat production by two mammals with contrasting coat colours. J Exp Biol. 1995;198:1499-507.

38. Buffington DE, Collazo-Arocho A, Canton GH, Pitt D. Black globehumidity index (bghi) as comfort equation for dairy cows. Trans ASAE. 1981;24:711-4.

39. Gaughan JB, Mader TL, Holt SM, Lisle A. A new heat load index for feedlot cattle. J Anim Sci. 2008;86:226-34. https://doi.org/10.2527/ jas.2007-0305.

40. Mader T, Johnson L, Gaughan J. A comprehensive index for assessing environmental stress in animals. J Anim Sci. 2010;88:2153-65.

41. Wang X, Gao H, Gebremedhin KG, Bjerg BS, Van Os J, Tucker CB, et al. A predictive model of equivalent temperature index for dairy cattle (etic). J Therm Biol. 2018;76:165-70.

42. Wijffels G, Sullivan M, Gaughan J. Methods to quantify heat stress in ruminants: current status and future prospects. Methods. 2020. https:// doi.org/10.1016/j.ymeth.2020.09.004.
43. Gaughan JB, Perkins N, Woldeyohannes S. Evaluation of a heat load model for feedlot cattle. North Sydney. 2019.

44. Schüller LK, Burfeind O, Heuwieser W. Comparison of ambient temperature, relative humidity, and temperature-humidity index between on-farm measurements and official meteorological data. J Dairy Sci. 2013;96:7731-8.

45. Adriaan Bouwknecht J, Olivier B, Paylor RE. The stress-induced hyperthermia paradigm as a physiological animal model for anxiety: a review of pharmacological and genetic studies in the mouse. Neurosci Biobehav Rev. 2007;31:41-59. https://doi.org/10.1016/j.neubi orev.2006.02.002.

46. McCafferty DJ, Gallon S, Nord A. Challenges of measuring body temperatures of free-ranging birds and mammals. Anim Biotelemetry. 2015;3:1-10. https://doi.org/10.1186/s40317-015-0075-2.

47. Reuter RR, Carroll JA, Hulbert LE, Dailey JW, Galyean ML. Technical note: development of a self-contained, indwelling rectal temperature probe for cattle research. J Anim Sci. 2010;88:3291-5. https://doi.org/10.2527/ jas.2010-3093.

48. Taylor NA, Tipton MJ, Kenny GP. Considerations for the measurement of core, skin and mean body temperatures. J Therm Biol. 2014;46:72-101. https://doi.org/10.1016/j.jtherbio.2014.10.006.

49. Vickers LA, Burfeind $O$, von Keyserlingk MA, Veira DM, Weary DM, Heuwieser W. Technical note: comparison of rectal and vaginal temperatures in lactating dairy cows. J Dairy Sci. 2010;93:5246-51. https://doi. org/10.3168/jds.2010-3388.

50. Suthar V, Burfeind O, Maeder B, Heuwieser W. Agreement between rectal and vaginal temperature measured with temperature loggers in dairy cows. J Dairy Res. 2013;80:240-5. https://doi.org/10.1017/S0022 029913000071.

51. Pent GJ, Fike JH, Kim I. Ewe lamb vaginal temperatures in hardwood silvopastures. Agrofor Syst. 2018. https://doi.org/10.1007/s1045 7-018-0221-y.

52. Emmanuel AV, Kamm MA, Beard RW. Reproducible assessment of vaginal and rectal mucosal and skin blood flow: laser doppler fluximetry of the pelvic microcirculation. Clin Sci. 2000;98:201-7. https://doi. org/10.1042/cs0980201.

53. Godfrey RW, Preston WD, Joseph SR, LaPlace L, Hillman PE, Gebremedhin $\mathrm{KG}$, et al. Evaluating the impact of breed, pregnancy, and hair coat on body temperature and sweating rate of hair sheep ewes in the tropics 1. J Anim Sci. 2017;95:2936-42. https://doi.org/10.2527/ jas.2016.1125.

54. Godyn D, Herbut P, Angrecka S. Measurements of peripheral and deep body temperature in cattle—a review. J Therm Biol. 2019;79:42-9. https ://doi.org/10.1016/j.jtherbio.2018.11.011.

55. I pema AH, Goense D, Hogewerf PH, Houwers HWJ, van Roest H. Pilot study to monitor body temperature of dairy cows with a rumen bolus. Comput Electron Agric. 2008;64:49-52. https://doi.org/10.1016/j.compa g.2008.05.009.

56. AlZahal O, AlZahal H, Steele MA, Van Schaik M, Kyriazakis I, Duffield TF, et al. The use of a radiotelemetric ruminal bolus to detect body temperature changes in lactating dairy cattle. J Dairy Sci. 2011;94:3568-74. https://doi.org/10.3168/jds.2010-3944.

57. AlZahal O, Steele MA, Valdes EV, McBride BW. Technical note: the use of a telemetric system to continuously monitor ruminal temperature and to predict ruminal ph in cattle. J Dairy Sci. 2009;92:5697-701. https:// doi.org/10.3168/jds.2009-2220.

58. Bewley JM, Einstein ME, Grott MW, Schutz MM. Comparison of reticular and rectal core body temperatures in lactating dairy cows. J Dairy Sci. 2008;91:4661-72. https://doi.org/10.3168/jds.2007-0835.

59. Small JA, Kennedy AD, Kahane SH. Core body temperature monitoring with passive transponder boluses in beef heifers. Can J Anim Sci. 2008;88:225-35. https://doi.org/10.4141/CJAS07023.

60. Boehmer BH, Pye TA, Wettemann RP. Ruminal temperature as a measure of body temperature of beef cows and relationship with ambient temperature. Prof Anim Sci. 2015;31:387-93. https://doi.org/10.15232/ pas.2014-01336.

61. Ammer S, Lambertz C, Gauly M. Is reticular temperature a useful indicator of heat stress in dairy cattle? J Dairy Sci. 2016;99:10067-76. https:// doi.org/10.3168/jds.2016-11282.

62. Vázquez-Diosdado J, Miguel-Pacheco G, Plant B, Dottorini T, Green $M$, Kaler J. Developing and evaluating threshold-based algorithms to 
detect drinking behavior in dairy cows using reticulorumen temperature. J Dairy Sci. 2019;102:10471-82.

63. Hanušovský O, Bíro D, Šimko M, Gálik B, Juráček M, Rolinec M, et al. Drinking regime evaluation with continuous ruminal monitoring boluses. Acta fytotechnica et zootechnica. 2017;20:1-5. https://doi. org/10.15414/afz.2017.20.01.01-05.

64. Burgos MS, Senn M, Sutter F, Kreuzer M, Langhans W. Effect of water restriction on feeding and metabolism in dairy cows. Am J Physiol Regul Integr Comp Physiol. 2001;280:418-R27. https://doi.org/10.1152/ ajpregu.2001.280.2.r418.

65. Hyder I, Ravi Kanth Reddy P, Raju J, Manjari P, Srinivasa Prasad C, Aswani Kumar K, et al. Alteration in rumen functions and diet digestibility during heat stress in sheep. In: Sejian V, Bhatta R, Gaughan J, Malik PK, Naqvi SMK, Lal R, eds. Sheep production adapting to climate change Singapore: Springer Nature; 2017. p. 235-65.

66. Beatty DT, Barnes A, Fleming PA, Taylor E, Maloney SK. The effect of fleece on core and rumen temperature in sheep. J Therm Biol. 2008:33:437-43. https://doi.org/10.1016/j.jtherbio.2008.07.002.

67. Beatty DT, Barnes A, Taylor E, Maloney SK. Do changes in feed intake or ambient temperature cause changes in cattle rumen temperature relative to core temperature? J Therm Biol. 2008;33:12-9. https://doi. org/10.1016/j.jtherbio.2007.09.002.

68. Dale HE, Stewart RE, Brody S. Rumen temperature. 1. Temperature gradients during feeding and fasting. Cornell Vet. 1954;44:368-74

69. Gonzalez-Rivas PA, DiGiacomo K, Giraldo PA, Leury BJ, Cottrell JJ, Dunshea FR. Reducing rumen starch fermentation of wheat with three percent sodium hydroxide has the potential to ameliorate the effect of heat stress in grain-fed wethers. J Anim Sci. 2017;95:5547-62. https:// doi.org/10.2527/jas2017.1843.

70. Macías-Cruz U, Correa-Calderón A, Mellado M, Meza-Herrera CA, Aréchiga CF, Avendaño-Reyes L. Thermoregulatory response to outdoor heat stress of hair sheep females at different physiological state. Int J Biometeorol. 2018;62:2151-60. https://doi.org/10.1007/s0048 4-018-1615-2.

71. Ghirardi JJ, Caja G, Garín D, Hernández-Jover M, Ribó O, Casellas J. Retention of different sizes of electronic identification boluses in the forestomachs of sheep. J Anim Sci. 2006;84:2865-72. https://doi. org/10.2527/jas.2006-157.

72. Tan J, Ng EYK, Rajendra Acharya U, Chee C. Infrared thermography on ocular surface temperature: a review. Infrared Phys Technol. 2009;52:97108. https://doi.org/10.1016/j.infrared.2009.05.002.

73. Lawson R. Implications of surface temperatures in the diagnosis of breast cancer. Can Med Assoc J. 1956;75:309-11.

74. McManus CM, Tanure CB, Peripolli V, Seixas L, Fischer V, Gabbi AM, et al. Infrared thermography in animal production: an overview. Comput Electron Agric. 2016;123:10-6. https://doi.org/10.1016/j.compa g.2016.01.027.

75. Soerensen DD, Pedersen $L$ J. Infrared skin temperature measurements for monitoring health in pigs: a review. Acta Vet Scand. 2015;57:1-11. https://doi.org/10.1186/s13028-015-0094-2.

76. Thwaites $C J$. Fleece length and the reactions of sheep to wet and dry heat. Nature (London). 1966;211:997-8. https://doi.org/10.1038/21199 $7 \mathrm{a} 0$.

77. Schaefer AL, Cook N, Tessaro SV, Deregt D, Desroches G, Dubeski $\mathrm{PL}$, et al. Early detection and prediction of infection using infrared thermography. Can J Anim Sci. 2004;84:73-80. https://doi.org/10.4141/ A02-104.

78. de Diego ACP, Sánchez-Cordón PJ, Pedrera M, Martínez-López B, Gómez-Villamandos JC, Sánchez-Vizcaíno JM. The use of infrared thermography as a non-invasive method for fever detection in sheep infected with bluetongue virus. Vet J. 2013;198:182-6. https://doi. org/10.1016/j.tvjl.2013.07.013.

79. Turner TA. Thermography as an aid to the clinical lameness evaluation. Veterinary Clin North Am Equine Pract. 1991;7:311-38. https://doi. org/10.1016/S0749-0739(17)30502-3.

80. Martins RFS, do Paim PT, de Cardoso AC, Dallago BSL, de Melo CB, Louvandini $\mathrm{H}$, et al. Mastitis detection in sheep by infrared thermography. Res Vet Sci. 2013;94:722-4. Doi: https://doi.org/10.1016/j. rvsc.2012.10.021
81. Colak A, Polat B, Okumus Z, Kaya M, Yanmaz LE, Hayirli A. Early detection of mastitis using infrared thermography in dairy cows. J Dairy Sci. 2008;91:4244-8. https://doi.org/10.3168/jds.2008-1258.

82. Ahirwar MK, Kataktalware MA, Pushpadass HA, Jeyakumar S, Jash S, Nazar S, et al. Scrotal infrared digital thermography predicts effects of thermal stress on buffalo (bubalus bubalis) semen. J Therm Biol. 2018;78:51-7. https://doi.org/10.1016/j.jtherbio.2018.09.003.

83. Brown-Brandl TM, Eigenberg RA, Purswell JL. Using thermal imaging as a method of investigating thermal thresholds in finishing pigs. Biosys Eng. 2013;114:327-33. https://doi.org/10.1016/j.biosystems eng.2012.11.015.

84. Stelletta C, Vencato J, Fiore E, Gianesella M. Infrared thermography in reproduction. Thermography. 2013:113-25.

85. George WD, Godfrey RW, Ketring RC, Vinson MC, Willard ST. Relationship among eye and muzzle temperatures measured using digital infrared thermal imaging and vaginal and rectal temperatures in hair sheep and cattle. J Anim Sci. 2014;92:4949-55. https://doi.org/10.2527/ jas.2014-8087.

86. Abecia JA, Pascual-Alonso M, Aguayo-Ulloa LA, Maria GA. Comparison of several devices to measure body temperature in sheep. Prec Livest Farm. 2015:221-9.

87. de Freitas BAC, Vega OWH, Quirino CR, Bartholazzi A Jr., David GCM, Geraldo AT, et al. Surface temperature of ewes during estrous cycle measured by infrared thermography. Theriogenology. 2018;1 19:245-51. https://doi.org/10.1016/j.theriogenology.2018.07.015.

88. Lees A, Sullivan M, Olm J, Cawdell-Smith A, Gaughan J. A panting score index for sheep. Int J Biometeorol. 2019;63:973-8.

89. Stewart M, Wilson MT, Schaefer AL, Huddart F, Sutherland MA. The use of infrared thermography and accelerometers for remote monitoring of dairy cow health and welfare. J Dairy Sci. 2017;100:3893-901. https:// doi.org/10.3168/jds.2016-12055.

90. Lee Y, Bok JD, Lee HJ, Lee HG, Kim D, Lee I, et al. Body temperature monitoring using subcutaneously implanted thermo-loggers from holstein steers. Asian-Australasian Association of Animal Production Societies; 2016. Report No.: 1011-2367 Contract No.: 2.

91. Reid $\mathrm{E}$. The use of implantable microchips for body temperature collection in cattle [PhD Thesis]. Urbana, Illinois: University of Illinois; 2014.

92. Chen PH, White CE. Comparison of rectal, microchip transponder, and infrared thermometry techniques for obtaining body temperature in the laboratory rabbit (oryctolagus cuniculus). J Am Assoc Lab Anim Sci. 2006:45:57-63.

93. Kellogg DL. In vivo mechanisms of cutaneous vasodilation and vasoconstriction in humans during thermoregulatory challenges. J Appl Physiol. 2006;100:1709-18. https://doi.org/10.1152/japplphysiol.01071 2005.

94. Kou H, Zhao Y, Ren K, Chen X, Lu Y, Wang D. Automated measurement of cattle surface temperature and its correlation with rectal temperature (research article)(report). PLoS One. 2017;12:e0175377-e87. https:// doi.org/10.1371/journal.pone.0175377.

95. Brinnel $\mathrm{H}$, Cabanac M. Tympanic temperature is a core temperature in humans. J Therm Biol. 1989;14:47-53. https://doi.org/10.1016/03064565(89)90029-6.

96. Drew ML. The use of a tympanic membrane thermometer for assessing hyperthermia in bighorn sheep. J Wild Dis. 1996;32:512-6. https://doi. org/10.7589/0090-3558-32.3.512.

97. Richeson JT, Powell JG, Kegley EB, Hornsby JA. Evaluation of an earmounted tympanic thermometer device for bovine respiratory disease diagnosis. Fayetteville, AR: University of Arkanas System; 2011.

98. Davis M, Mader T, Holt S, Parkhurst A. Strategies to reduce feedlot cattle heat stress: effects on tympanic temperature. J Anim Sci. 2003;81:64961. https://doi.org/10.2527/2003.813649x.

99. Mayer JJ, Davis JD, Purswell JL, Koury EJ, Younan NH, Larson JE, et al. Development and characterization of a continuous tympanic temperature logging (cttl) probe for bovine animals. Trans ASABE. 2016;59:70314. https://doi.org/10.13031/trans.59.11367.

100. Bergen RD, Kennedy AD. Relationship between vaginal and tympanic membrane temperature in beef heifers. Can J Anim Sci. 2000;80:515-8. https://doi.org/10.4141/A00-033.

101. Gougoulis DA, Kyriazakis I, Fthenakis GC. Diagnostic significance of behaviour changes of sheep: a selected review. Small Rumin Res. 2010;92:52-6. https://doi.org/10.1016/j.smallrumres.2010.04.018. 
102. Marais J, Le Roux SP, Wolhuter R, Niesler T, editors. Automatic classification of sheep behaviour using 3-axis accelerometer data. Proceedings of the twenty-fifth annual symposium of the Pattern Recognition Association of South Africa (PRASA); 2014.

103. Decandia M, Giovanetti V, Molle G, Acciaro M, Mameli M, Cabiddu A, et al. The effect of different time epoch settings on the classification of sheep behaviour using tri-axial accelerometry. Comput Electron Agric. 2018;154:112-9. https://doi.org/10.1016/j.compag.2018.09.002.

104. Yang C, Hsu Y. A review of accelerometry-based wearable motion detectors for physical activity monitoring. Sensors. 2010;10:7772-88. https://doi.org/10.3390/s100807772.

105. Giovanetti V, Decandia M, Molle G, Acciaro M, Mameli M, Cabiddu A, et al. Automatic classification system for grazing, ruminating and resting behaviour of dairy sheep using a tri-axial accelerometer. Livest Sci. 2017;196:42-8. https://doi.org/10.1016/j.livsci.2016.12.011.

106. Barwick J, Lamb DW, Dobos RC, Welch M, Trotter M. Categorising sheep activity using a tri-axial accelerometer. Comput Electron Agric. 2018;145:289-97. https://doi.org/10.1016/j.compag.2018.01.007.

107. Umstätter C, Waterhouse A, Holland JP. An automated sensor-based method of simple behavioural classification of sheep in extensive systems. Comput Electron Agric. 2008;64:19-26. https://doi.org/10.1016/j. compag.2008.05.004.

108. Fogarty ES, Swain DL, Cronin GM, Moraes LE, Trotter MG. Can accelerometer ear tags identify behavioural changes in sheep associated with parturition? Anim Reprod Sci. 2020;216:106345-58. https://doi. org/10.1016/j.anireprosci.2020.106345

109. Paganoni B, Macleay C, van Burgel A, Thompson A. Proximity sensors fitted to ewes and rams during joining can indicate the birth date of lambs. Comput Electron Agric. 2020;170:105249.

110. Sohi R, Trompf J, Marriott H, Bervan A, Godoy B, Weerasinghe M, et al. Determination of maternal pedigree and ewe-lamb spatial relationships by application of bluetooth technology in extensive farming systems. J Anim Sci. 2017;95:5145-50.

111. Gaughan JB, Holt S, Hahn GL, Mader TL, Eigenberg RA. Respiration rate: Is it a good measure of heat stress in cattle? Asian-Australas J Anim Sci. 2000;13:329-32.

112. Barwick J, Lamb DW, Trotter M, Dobos RC. On-animal motion sensing using accelerometers as a tool for monitoring sheep behaviour and health status (PhD Thesis). Armidale: University of New England; 2017.

113. Handcock RN, Swain DL, Bishop-Hurley GJ, Patison KP, Wark T, Valencia $P$, et al. Monitoring animal behaviour and environmental interactions using wireless sensor networks, gps collars and satellite remote sensing. Sensors. 2009;9:3586-603. https://doi.org/10.3390/s90503586.

114. Fogarty ES, Swain DL, Cronin GM, Trotter MG. Autonomous on-animal sensors in sheep research: a systematic review. Comput Electron Agric. 2018;150:245-56. https://doi.org/10.1016/j.compag.2018.04.017.

115. Williams B, Walsh M, Gormally M, Walls S, Sheahan J. Resource selection by hill sheep: direct flock observations versus gps tracking. Appl Ecol Environ Res. 2010;8:279-300. https://doi.org/10.15666/ aeer/0804_279299.

116. Hulbert IAR, Wyllie JTB, Waterhouse A, French J, McNulty D. A note on the circadian rhythm and feeding behaviour of sheep fitted with a lightweight gps collar. Appl Anim Behav Sci. 1998;60:359-64. https:// doi.org/10.1016/S0168-1591(98)00155-5.

117. Bailey DW, Trotter MG, Knight CW, Thomas MG. Use of gps tracking collars and accelerometers for rangeland livestock production research. J Anim Sci. 2017;95:360-1. https://doi.org/10.2527/asasann.2017.740.
118. Fogarty ES, Manning JK, Trotter MG, Schneider DA, Thomson PC, Bush $\mathrm{RD}$, et al. Gnss technology and its application for improved reproductive management in extensive sheep systems. Anim Prod Sci. 2015;55:1272-80. https://doi.org/10.1071/AN14032.

119. Johnson KG. Body temperatures and respiratory rates of free-ranging merino sheep in and out of shade during summer. Aust J Agric Res. 1991;42:1347-57. https://doi.org/10.1071/AR9911347.

120. Brown-BrandI TM, Eigenberg RA, Nienaber JA, Hahn GL. Dynamic response indicators of heat stress in shaded and non-shaded feedlot cattle, part 1: analyses of indicators. Biosys Eng. 2005;90:451-62. https:// doi.org/10.1016/j.biosystemseng.2004.12.006.

121. Thomas DT, Wilmot MG, Alchin M, Masters DG. Preliminary indications that merino sheep graze different areas on cooler days in the southern rangelands of western australia. Aust J Exp Agric. 2008;48:889-92. https ://doi.org/10.1071/EA08061.

122. Blackshaw JK, Blackshaw AW. Heat stress in cattle and the effect of shade on production and behaviour: a review. Aust J Exp Agric. 1994;34:285-95. https://doi.org/10.1071/EA9940285.

123. Stockman CA. The physiological and behavioural responses of sheep exposed to heat load within intensive sheep industries (PhD Thesis). Western Australia: Murdoch University; 2006.

124. Lowe TE, Cook CJ, Ingram JR, Harris PJ. Impact of climate on thermal rhythm in pastoral sheep. Physiol Behav. 2001;74:659-64.

125. Bernabucci U, Lacetera N, Danieli PP, Bani P, Nardone A, Ronchi B. Influence of different periods of exposure to hot environment on rumen function and diet digestibility in sheep. Int J Biometeorol. 2009;53:387-95.

126. Lees A, Sullivan M, Olm J, Cawdell-Smith A, Gaughan J. The influence of heat load on merino sheep. 2. Body temperature, wool surface temperature and respiratory dynamics. Anim Prod Sci. 2020;60:1932-9.

127. Goodwin SD. Comparison of body temperatures of goats, horses, and sheep measured with a tympanic infrared thermometer, an implantable microchip transponder, and a rectal thermometer. J Am Assoc Lab Anim Sci. 1998;37:51-5.

128. Paim TDP, Borges BO, Lima PMT, Dallago BSL, Louvandini H, McManus CM. Relation between thermographic temperatures of lambs and thermal comfort indices. Int J Appl Anim Sci. 2012;1:108-15.

129. Paim TDP, Borges BO, Lima PDMT, Gomes EF, Dallago BSL, Fadel R, et al. Thermographic evaluation of climatic conditions on lambs from different genetic groups. Int J Biometeorol. 2013;57:59-66. https://doi. org/10.1007/s00484-012-0533-y.

130. Vicente-Perez R, Avendano-Reyes L, Mejia-Vazquez A, Álvarez-Valenzuela FD, Correa-Calderon A, Mellado M, et al. Prediction of rectal temperature using non-invasive physiologic variable measurements in hair pregnant ewes subjected to natural conditions of heat stress. J Therm Biol. 2016:55:1-6. https://doi.org/10.1016/j.jtherbio.2015.11.004.

131. Rayas-Amor AA, Morales-Almaráz E, Licona-Velázquez G, Vieyra-Alberto R, García-Martínez A, Martínez-García CG, et al. Triaxial accelerometers for recording grazing and ruminating time in dairy cows: an alternative to visual observations. J Vet Behav. 2017;20:102-8. https://doi. org/10.1016/j.jveb.2017.04.003.

\section{Publisher's Note}

Springer Nature remains neutral with regard to jurisdictional claims in published maps and institutional affiliations. 